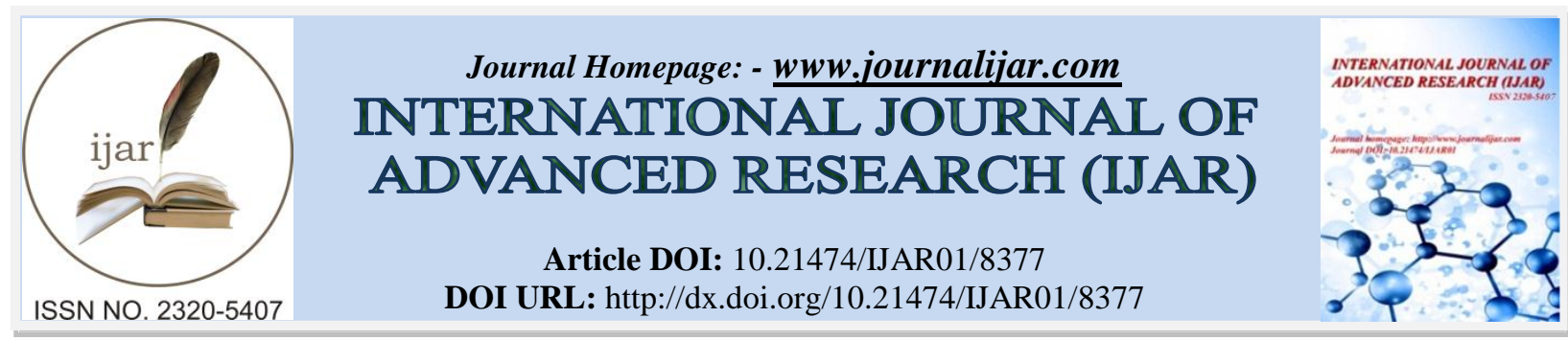

RESEARCH ARTICLE

\title{
DEMOGRAPHIC FEATURES AND ETIOLOGY OF WOMEN HAVING PELVIC GIRDLE PAIN AND LOW BACK PAIN IN PREGNANCY.
}

\section{Rashi Rashi ${ }^{1}$, R K Prasad ${ }^{2}$ and Mayank Kumar ${ }^{3}$.}

1. Senior resident, Department of Obstetrics \& Gynecology, Katihar Medical College and hospital, Katihar, Bihar.

2. Assistant Proffessor, Department of Orthopedics ,Darbhanga medical college and hospital, Darbhanga ,bihar.

3. Consultant Neurosurgeon , and spine surgeon, Darbhanga medical college and hospital, Darbhanga ,bihar.

\section{Manuscript Info}

n........................

Manuscript History

Received: 10 November 2018

Final Accepted: 12 December 2018

Published: January 2019

Key words:-

pelvic girdlepain, lowback pain, prevalence.

\section{Abstract}

Introduction:Symphysis pubis dysfunction (spd) has been recog nized as an obstetric condition since the time of hip-pocrates. In spite of this long history, many medical staff remain unaware of the condition. Women continue to suffer from symphysis pubis pain with considerable reduction in quality of life during pregnancy. In recent years there has been an upsurge in the reported incidence of spd partly due to gross pre- vious under recognition.

Methodology:This is a retrospective observational study.in this study we studied a total of 56 pregnant women, who were referred to department of orthopedics of darbhanga medical college and hospital, for back pain, over a period of 6 months, from january 2018 to july 2018.the obsterical team referred the patients , after ruling out obstetric complications (preterm labor, abruption, red degeneration of uterine fibroid, round ligament pain, and chorioamnionitis), and urinary tract infections

Observations:Most of the patients were aged 25-30, and maximum patients were second or third time pregnant. This table shows that the maximum no $28 / 56(50 \%)$ of patients had pelvic girdle pain, followed by plbp $15 / 56(26.78 \%)$.

$39 / 56(70 \%)$ of paients were relieved by these simple measures, and physical therapy. Pharmacotherapy. A total of 12/56 (21.42\%) patients needed pharmacotherapy.

Conclusion:Pgp and plbp are common problems, but they are often underestimated and undertreated. A large number of terms for these conditions have been used in the literature, and there is a need for a uniform terminology in order to promote research and management of these conditions

Copy Right, IJAR, 2018,. All rights reserved.

\section{Introduction:-}

Symphysis pubis dysfunction (SPD) has been recog nized as an Obstetric condition since the time of Hip- pocrates. In spite of this long history, many medical staff remain unaware of the condition. Women continue to suffer from

Corresponding Author:-Rashi Rashi.

Address:-Senior resident ,Department of Obstetrics \& Gynecology, Katihar Medical College and hospital, Katihar, Bihar. 
symphysis pubis pain with considerable reduction in quality of life during pregnancy. In recent years there has been an upsurge in the reported incidence of SPD partly due to gross pre- vious under recognition

The symphysis pubis is a non-synovial cartilaginous joint. The stability of this joint is integral to the function of the pelvis. SPD occurs when the symphysis pubis is unable to effectively perform its role in pelvic stabilization. The wide variation in the incidence of SPD quoted in the lit- erature is due in part to the various names given to this condition.

\section{Epidemiology}

In one studyof the British population, the incidence of SPD varies from 1:360.3\% to $2.77 \%$.(1)

Although the vast majority of studies on PGP/PLBP has been carried out in Scandinavia, studies have also been carried out in The Netherlands, (2)the U.S.A.,(3) the U.K.,(4) Australia,(5) Africa,(6) Iran,(7) and Israel,(8)indicating that PGP and PLBP are universal problems.(9)Studies report a wide range of prevalence (4\% to $76 \%$ ) of PGP and/or PLBP.(10)This variation is a result of the criteria employed by various studies for the diagnosis of PGP and/or PLBP (patient self-report, doctor's report, or history and clinical examination as diagnostic criteria), design of the study (prospective or retrospective), sample size, and location of the pain in the back.(10)

\section{Pathology}

The atieology of Symphysis pubis pain remains unknown. It is however well known that during pregnancy there is relaxation and weakness of pelvic ligaments and joints under the influence of maternal hormones (mainly rela- xin). Pelvic ligament weakness leads to instability in the joints. This instability may be sufficient to cause the movement of the bone ends at the symphysis pubis thus stimulating mechanoreceptors with a nociceptive function and resulting in pain. The articular surfaces of the pubic joint are lined with a thin layer of hyaline cartilage and joined by a fibrocartilaginous disc resulting in an average gap of about $5 \mathrm{~mm}$ between the pubic bodies [11]. This interpubic gap increases by an average of about $3 \mathrm{~mm}$ by the third trimester of pregnancy returning back to non-pregnant dimensions by 3 to 6 months after deliv- ery. A pubic gap of more than $10 \mathrm{~mm}$ is often quoted as being abnormal [12].

\section{Clinical Features}

PGP and PLBP usually start around the 18th week of pregnancy (peak intensity between 24th and 36th weeks), but can also start in the first trimester or be delayed as late as 3 weeks after delivery.(13)

PLBP is characterized by lumbar region pain. It is dull in character and is experienced when the patient is in forward flexion. There is restriction of spine movement inthelumbarregion, andpalpationoftheerectorspinae muscles exacerbates pain.6 The pain resembles the back pain that occurs in the nonpregnant state.(14)

PGP Vleeming et al. have defined PGP as: "In PGP pain is experienced in-between the posterior iliac crest and the gluteal fold, particularly in the vicinity of the sacroiliac joints (SIJ). The pain may radiate into the posterior thigh and can also occur in conjunction with/or separately in the symphysis pubis."(15) The pain has been described as stabbing, shooting, dull, or burning.(16)The average visual analog score for pain is $50 \mathrm{~mm}$ to $60 \mathrm{~mm}$ on a $100-\mathrm{mm}$ scale.(17)

Making The Diagnosis

Excluding Serious Pathology For women presenting with low back pain and/or pelvic pain in pregnancy, a thorough history and physical examination should be carried out. The aim is to exclude other causes of pain (Table 3), to differentiate between PGP and PLBP, to assess disability, and to formulate an individualized management plan.

Table 1:-Differential Diagnosis of PGP and PLBP

\begin{tabular}{|l|l|}
\hline Urinary tract infection & Spondylolisthesis \\
\hline Osteomyelitis & Pregnancy-associated osteoporosis \\
\hline Lumbar disk lesion/prolapse & Femoral vein thrombosis \\
\hline Arthritis of spine/hip & Osteitis pubis \\
\hline
\end{tabular}




\begin{tabular}{|l|l|}
\hline $\begin{array}{l}\text { Lumbar stenosis } \\
\text { Cauda equina syndrome }\end{array}$ & $\begin{array}{l}\text { Rupture of symphysis pubis } \\
\text { Sciatica }\end{array}$ \\
\hline $\begin{array}{l}\text { Obstetric complications (preterm labor, abruption, red } \\
\text { degeneration of uterine fibroid, round ligament pain, and } \\
\text { chorioamnionitis) }\end{array}$ & \\
\hline & \\
\hline
\end{tabular}

\section{PGP, pregnancy-related pelvic girdle pain; PLBP, pregnancy-related low back pain.}

Pain Provocation Tests A number of pain provocation tests have been described for the diagnosis of PGP. Majority of these tests have high specificity but low sensitivity,(10)indicating that if a test is negative, then the patient is unlikely to have PGP. It is recommended to perform as many tests as possible, taking into account the low sensitivity of the tests.(10)The posterior pelvic pain provocation test, Patrick's test, and the long dorsal sacroiliac ligament test are recommended for the diagnosis of the pain in the region of SIJs.(18) For pubic symphysis pain, direct palpation of the symphysis pubis, modified Trendelenberg's test, and active straight leg raising tests are recommended.(18).

\section{Methodology:-}

This is a retrospective observational study.In this study we studied a total of 56 pregnant women, who were referred to Department of Orthopedics of Darbhanga Medical College and Hospital, for back pain, over a period of 6 months, from January 2018 to july 2018. The Obsterical team referred the patients , after ruling out Obstetric complications (preterm labor, abruption, red degeneration of uterine fibroid, round ligament pain, and chorioamnionitis), and urinary tract infections

\section{Observations:-}

Table 2:-Demographic details of the patients

\begin{tabular}{|l|l|l|}
\hline Age in years & No of patients(n-56) & percentage \\
\hline $20-25$ & 22 & 39.28 \\
\hline $25-30$ & 19 & 33.92 \\
\hline $30-35$ & 15 & 26.78 \\
\hline parity & & \\
\hline P1 & 8 & 14.28 \\
\hline P2-3 & 22 & 39.28 \\
\hline P4 and above & 16 & 28.57 \\
\hline
\end{tabular}

So we can say that most of the patients were aged 25-30, and maximum patients were second or third time pregnant.

Table 3:-Definite Diagnosis of the patients with back ache with pain provocation tests

\begin{tabular}{|l|l|l|}
\hline Diagnosis & No of patients(n-56) & percentage \\
\hline Pelvic girdle pain & 28 & 50 \\
\hline Pregnancy related low back pain(PLBP) & 15 & 26.78 \\
\hline Osteomyelitis & 2 & 3.57 \\
\hline $\begin{array}{l}\text { Lumbar disk lesion/prolapse, Lumbar stenosis } \\
\text { Cauda equina syndrome } \\
\text { Spondylolisthesis }\end{array}$ & 1 & 1.78 \\
\hline $\begin{array}{l}\text { Arthritis of spine/hip } \\
\text { Pregnancy associated osteoporosis }\end{array}$ & 3 & 5.35 \\
\hline others & 2 & 3.57 \\
\hline
\end{tabular}


This table shows that the maximum no 28/56 (50\%) of patients had pelvic girdle pain, followed by PLBP $15 / 56(26.78 \%)$.

Treatment Options

Table 4:-Various treatment measures offered to patient

\begin{tabular}{|l|l|l|}
\hline Treatment modality & No of patients & percentage \\
\hline simple measures, and physical therapy & $39 / 56$ & $70 \%$ \\
\hline Pharmacotherapy & $12 / 56$ & $21.42 \%$ \\
\hline No treatment found effective & $5 / 56$ & $8.92 \%$ \\
\hline
\end{tabular}

The following simple measures were found very useful to patients. $39 / 56(70 \%)$ of paients were relieved by these simple measures, and physical therapy

- keeping active but also getting plenty of rest $\bullet$ standing tall with your bump and bottom tucked in a little $\bullet$ changing your position frequently - try not to sit for more than 30 minutes at a time $\bullet$ sitting to get dressed and undressed $\bullet$ putting equal weight on each leg when you stand • trying to keep your legs together when getting in and out of the car $\bullet$ lying on the less painful side while sleeping • keeping your knees together when turning over in bed $\bullet$ using a pillow under your bump and between your legs for extra support in bed. One should avoid anything that may make your symptoms worse, such as: • lifting anything heavy, for example heavy shopping • going up and down the stairs too often $3 \cdot$ stooping, bending or twisting to lift or carry a toddler or baby on one hip $\bullet$ sitting on the floor, sitting twisted, or sitting or standing for long periods $\bullet$ standing on one leg or crossing your legs.

\section{Physical Therapy.}

The use of devices as simple as a pillow in the shape of a nest has been found to be useful in decreasing pain and insomnia during late pregnancy.(19) The pillow supports the abdomen when the woman is in the lateral recumbent position and appears to relieve symptoms. Other devices that can be used include a lumbar roll placed behind the lower back (while resting with feet slightly elevated), abdominolumbar supports,(20) and sacroiliac belts.(21)

\section{Transcutaneous Electrical Nerve Stimulation.}

There are no randomized controlled trials of transcutaneous electrical nerve stimulation (TENS) in pregnancy except for in labor. There have been theoretical concerns about stimulation of certain acupuncture points (which have been used to induce labor), fetal malformations, and passage of current through fetal heart while using TENS. However, no negative effects have been reported from the use of TENS during any stage of pregnancy.(22)

No patients wew offered TENS or acupuncture, due to lack of resources and expertise

\section{Acupuncture.}

The use of acupuncture for PGP/PLBPis increasing.(23) Most studies are controlled trials of series of small numbers of patients, and they suffer potential bias from their lack of blinding of both the patient and the investigator .The acupuncturist must avoid certain acupuncture points in pregnancy that supply the cervix and uterus (which have been used to induce labor), but the technique in general is considered to be safe. The majority of the older studies has found that acupuncture provides effective analgesia to women with PGP and/or PLBP in pregnancy.(23) A recent randomized double-blinded controlled trial in 115 patients diagnosed with PGP has shown that acupuncture had no significant effect on pain or on the degree of sick leave compared with nonpenetrating sham acupuncture, although there was some improvement in performing daily activities.(24)However, acupuncture has been widely shown to be of benefit in the management of chronic lower back pain.(24)

\section{Pharmacotherapy. A total of 12/56 (21.42\%) patients needed pharmacotherapy.}

There are no studies on the use of drugs in PGP/PLBP in pregnancy. Although paracetamol is considered safe in pregnancy, it does not seem to be very effective on its own for these conditions. The use ofnonsteroidal antiinflammatory drugs (NSAIDs) is not associated with fetal malformations before 30 weeks of pregnancy. However, the majority of women is unlikely to require treatment for PGP/PLBP in early pregnancy. NSAIDs are generally withheld in the last trimester of pregnancy because of the risk of premature closure of the ductus arteriosus and the risk of oligohydramnios.(25) NSAIDs can be used safely after delivery in breast-feeding mothers. Opioids such as morphine, codeine, meperidine, tramadol, hydrocodone, fentanyl, propoxyphene, and oxymorphone are included in category $\mathrm{C}$ of the pregnancy risk category by the "Food and Drug Administration." The use of opioids in late 
pregnancy and in breast-feeding mothers can result in respiratory depression in the neonate, and withdrawal effects in newborns of mothers on long-term opioids.(26)

\section{Epidural Analgesia.}

There is a potential role for epidural analgesia in the management of severe PGP/PLBP, but it has not been properly evaluated and the evidence, as it is, is restricted to a few isolated case reports

\section{Induction of Labour}

Induction of labour (after 38 weeks gestation) is often offered as a last resort if nothing else works. Ultimately delivery always seems to eventually relieve the symp- toms of SPD. The potential for failed induction of labour (particularly in primiparas with an unfavourable cervix) must be discussed before induction of labour is embarked upon. It is important for both midwives and doctors to be aware of the implications of SPD during labour. Separation of legs should be kept to a minimum and vaginal examinations should be peformed in a position that is most com- fortable to the woman. The masking effect of epidural analgesia/spinal anaesthesia must always be remembered as it is quite easy to excessively abduct the hips if this is forgotten. Lithotomy, if recquired (e.g. for assisted deliv- ery or suturing) should be for the shortest time possible. Post-Natal Management Following delivery analgesia should be continued as symptoms may not resolve immediately. NSAIDS can now be used. Comprehensive physiotherapy may have to be continued for a few days before symptoms eventually disappear.

\section{Conclusion:-}

PGP and PLBP are common problems, but they are often underestimated and undertreated. A large number of terms for these conditions have been used in the literature, and there is a need for a uniform terminology in order to promote research and management of these conditions.

\section{References:-}

1. Owens K, Pearson A, Mason G. Symphysis pubis dysfunction - a cause of significant obstetric morbidity.Eur J Obstet Gynecol Reprod Biol 2002;105:143-46.

2. Mens JM, Vleeming A, Stoeckart R, Stam HJ, Snijders CJ. Understanding peripartum pelvic pain. Implications of a patient survey. Spine. 1996;21:1363-1369.

3. Wang S, Dezinno P, Maranets I, Berman MR, Caldwell-Andrews AA, Kain ZN. Low back pain during pregnancy: prevalence, risk factors, and outcomes. Obstet Gynecol. 2004;104:65-70.

4. Mantle MJ, Greenwood RM, Currey HL. Backache in pregnancy. Rheumatol Rehabil. 1977;16:95-101.

5. MacLennan AH, Nicolson R, Green RC, Bath M. Serum relaxin and pelvic pain of pregnancy. Lancet. 1986;2:243-245.

6. Bjourlund K, Bergstrom S. Is pelvic pain in pregnancy a welfare complaint? Acta Obstet Gynecol Scand. 2000;79:24-30.

7. Garshasbi A, Zadeh SF. The effect of exercise on the intensity of low back pain in pregnant women. Int $\mathbf{J}$ Gynaecol Obstet. 2005;88:271-275.

8. Orvieto R, Achiron A, Ben-Rafael Z, Gelernter I, AchironR.Lowbackpainofpregnancy.Acta Obstet Gynecol Scand. 1994;73:209-214.

9. Bastiaanssen JM, de Bie RA, Bastiaenen CH, Essed GG, van den Brandt PA. A historical perspective on pregnancy-related low back and/or pelvic girdle pain. Eur J Obstet Gynecol Reprod Biol. 2005;120:3-14.

10. Vleeming A, Albert HB, Ostgaard HC, Sturesson B, Stuge B. European guidelines for the diagnosis and treatment of pelvic girdle pain. Eur Spine J. 2008;17:794-819.

11. Fry, D. (1999) Perinatal symphysis pubis dysfunction: A women's health review of the literature. Journal of the Association of Chartered Physiotherapists, 85, 11-17.

12. Leadbetter, R.E., Mawer, D. and Lindow, S. (2004) Jour- nal of Maternal-Fetal \& Neonatal medicine, 16, 349355. doi:10.1080/jmf.16.6.349.354

13. Gutke A, Ostgaard HC, Oberg B. Pelvic girdle pain and lumbar pain in pregnancy: a cohort study of the consequences in terms of health and functioning. Spine. 2006;31:E149-E155.

14. Lile J, Perkins J, Hammer RL, Loubert PV. Diagnostic and management strategies for pregnant women with back pain. JAAPA. 2003;16:31-44

15. Vleeming A, Albert HB, Ostgaard HC, Sturesson B, Stuge B. European guidelines for the diagnosis and treatment of pelvic girdle pain. Eur Spine J. 2008;17:794-819. 
16. Rost CC, Jacqueline J, Kaiser A, Verhagen AP, Koes BW. Pelvic pain during pregnancy: a descriptive study of signs and symptoms of 870 patients in primary care. Spine. 2004;29:2567-2572.

17. Kristiansson P, Svardsudd K, von Schoultz B. Back pain during pregnancy: a prospective study. Spine. 1996; 21:702-708.

18. Vleeming A, Albert HB, Ostgaard HC, Sturesson B, Stuge B. European guidelines on the diagnosis and treatment of pelvic girdle pain [European Commission Research Directorate General Web site]. 2005. Available at: http://www. backpaineurope.org/web/files/WG4_Guidelines.pdf (accessed April 22, 2009).

19. Thomas IL, Nicklin J, Pollock H, Faulkner K. Evaluation of a maternity cushion (Ozzlo pillow) for backache and insomnia in late pregnancy. Aust N Z J Obstet Gynaecol. 1989;29:133-138.

20. Carr CA. Use of a maternity support binder for relief of pregnancy-related back pain. J Obstet Gynecol Neonatal Nurs. 2003;32:495-502

21. Ostgaard HC, Zetherstrom G, Roos-Hansson E, Svanberg B. Reduction of back and posterior pelvic pain in pregnancy. Spine. 1994;19:894-900.

22. Coldron Y, Crothers E, Haslam J, et al. ACPWH guidance on the safe use of transcutaneous electrical nerve stimulation (TENS) for musculosketal pain during pregnancy. 2007. Association of Chartered Physiotherapists in Women's Health(ACPWH)website.Availableat:http://www.oaa-anaes. ac.uk/assets/_managed/editor/File/PDF/info_for_mothers/ TENS\%20Statement\%20JUNE\%2007\%20ACPWH\%20 Final.pdf (accessed September 22, 2009).

23. Guerreiro da Silva JB, Nakamura MU, Cordeiro JA, Kulay L Jr. Acupuncture for low back pain in pregnancya prospective, quasi-randomised, controlled study. Acupunct Med. 2004;22:60-67.

24. Grant DJ, Bishop-Miller J, Winchester DM, Anderson M, Faulkner S. A randomized comparative trial of acupunctureversustranscutaneouselectricalnervestimulationfor chronic back pain in the elderly. Pain. 1999;82:9-13.

25. Stephens S. Use of non-steroidal anti-inflammatory drugs (NSAIDs) in pregnancy National electronic Library for Medicines Web site. 2008. Available at: http://www.nelm. nhs.uk/en/NeLM-Area/Evidence/Drugs-inPregnancy/Use-ofnon-steroidal-anti-inflammatory-drugs-NSAIDs-inpregnancy/ (accessed April 24, 2009).

26. British National Formulary. British National Formulary.53rded.Biggleswade,U.K.:RPSPublishing;2007: 785790. 